\title{
Single-incision (with multi-input single-port) laparoscopic colorectal procedures: Early results
}

\author{
Metin Ertem¹, Hakan Gök², Emel Özveri²
}

Objective: Single incision laparoscopic surgery (SILS) is a "scar-less" new surgical technique which has been gaining popularity over recent years. In comparison to conventional multiport laparoscopic surgery, SILS is introduced as a less invasive method. This technique has also been applied to colorectal surgery. The aim of the presenting study is to investigate the applicability of SILS and report short term results.

Material and Methods: We evaluated prospectively collected data of 24 patients who had been operated with "Single Incision Laparoscopic Colon Resection (SILCR)" in our clinic between June 2011-June 2013. Informed consent was obtained from all patients before surgery. Patient data such as ASA and BMI values, need for additional surgery, tumors, number of lymph nodes resected, length of hospital stay, length of surgery, timing of flatus, time to start oral feeding and complications were recorded.

Results: SILCR was performed in 24 patients. In 13 patients, SILCR was performed for cancer treatment. There was no need for extra ports, conversion to open surgery and stoma creation was also not necessary. Drain was placed in 4 patients. Overall complication rate was $12.5 \%$. The mean number of lymph nodes in 13 patients who underwent SILCR for tumor was found to be 23 (14-33). The mean operative time and length of hospital stay was 177 minutes (110-363) and 5.35 days (4-11) respectively. Anastomotic leakage was not seen in any of the patients. In one patient, urinoma formation due to ureteral leakage was seen which resulted from thermal injury.

Conclusion: When we compare other series with almost the same number of patients' reported SILS results in the literature, we believe that we could draw conclusions from our data. SILS appears to have comparable results to conventional multiport laparoscopic surgery in the hands of experienced surgeons. It seems advantegous as it can be done with conventional laparoscopic instruments in a "scar-less" manner. Prospective randomized trials are necessary to define the benefits of one procedure over the other.

Key Words: Single port, laparoscopic colorectal surgery, laparoscopic surgery

Istanbul University Cerrahpaşa Medical Faculty, Department of General Surgery, Istanbul, Turkey ${ }^{2}$ Acıbadem Kozyatağı Hospital, General Surgery Clinics, Istanbul, Turkey

\section{Address for Correspondence Dr. Metin Ertem}

Istanbul University Cerrahpaşa Medical Faculty, Department of General Surgery, Istanbul, Turkey Phone: +905323138085 e-mail:

metinertem@hotmail.com

Received: 27.07 .2013

Accepted: 11.08.2013

CCopyright 2013 by Turkish Surgical Association

Available online at

www.ulusalcerrahidergisi.org

\section{INTRODUCTION}

Expertise in laparoscopy over 20 years and the advances in technology expand the role of NOTES and single port or single incision surgeries within the spectrum of minimally invasive surgery. This technique has rapidly gained acceptance with support from flexible hand devices, telescopes with rotating ends and port systems that can be placed through $2-5 \mathrm{~cm}$ incisions without gas leakage. This technique was first used in right-hemicolectomy by Remzi et al. for a large cecal polyp (1). Similar to the way laparoscopic surgery began; single incision surgery was first used in cholecystectomy and gained popularity thereafter. Colorectal procedures with this method have also begun during the same period. According to results from studies on single incision surgical procedures, this method has a slight advantage over conventional laparoscopic procedures with less pain, less length of hospital stay and faster recovery (2-4).

\section{MATERIAL AND METHODS}

Single incision laparoscopic colorectal surgery (S-LCS) has been performed in 24 selected patients from June 2011 to June 2013. Patients were selected based on clinical assessment and computerized tomography findings. Those with ASA scores of I-II and with tumor size less than $6 \mathrm{~cm}$. According to preoperative radiologic evaluation were chosen for this procedure. Demographic data, informed consent and postoperative results were recorded (Table 1, 2).

Technique: Single port systems that can be placed through a single incision and that allows introduction of four instruments (one $12 \mathrm{~mm}$, one $10 \mathrm{~mm}$, two $5 \mathrm{~mm}$ ) have been used (OCTO ${ }^{\mathrm{Tm}}$ Port, Dalim Surgnet, Seoul, South Korea) (Figure 1). A $3 \mathrm{~cm}$ diameter OctoPort was used for benign pathologies whereas a $5 \mathrm{~cm}$ diameter OctoPort was preferred for malignancies. A semicircular incision of 3-5 cm was done around the umbilicus, without compromising the anatomy, and the port was placed in 
the abdominal wall. S-shaped retractors were used for placement of the port through the incision. A standard telescope of $10 \mathrm{~mm}$ size with $30^{\circ}$ angulation was used with adaptation of the light cable with a L-shaped downsizer. Dissection was started based on the promontorium for the left colon and right colic artery origin for the right colon. Dissections were carried out anatomically from medial to lateral. Main vessels were secured initially. The vascular pedicles were clipped as high as possible in all cases. LigaSure ${ }^{\mathrm{TM}} 5 \mathrm{~mm}-37 \mathrm{~cm}$ (Covidien Inc., Mansfield, Massachusetts, USA) was used for vessel sealing and dissection. The surgical steps of the procedures are identical to conventional laparoscopy once the port has been introduced. In all left sided procedures the left ureter has been viewed throughout its course, beginning from its origin. When the small bowel were causing difficulty, especially in the left colon and pelvis, a funnel shaped laparoscopic retractor (Covidien Inc., Mansfield, USA) was introduced through the fourth channel of the port. In one patient where the vision was impaired by the uterus, it was hanged to the abdominal wall by T- pea lifter suture (Protomed, Marsilya, France) to gain exposition.

The terminal ileum was transected via linear Echelon Flex $60 \mathrm{~mm}$ Stapler, Blue Cartridge (Ethicon Endo-Surgery, Inc., Blue Ash, Ohio, USA) in right sided colon resections. The right colon was resected by taking this segment out of the port. Dissection was carried out without difficulty by using straight laparoscopic instruments based on features related to the design of the port. Moreover the port itself provided wound isolation when the specimen was taken out, with no further requirement for protective Alexis (Figure 2). The surgical specimen of both the right and the left colon was taken out through the port and transected at the previously determined level. The anastomoses after right colonic resection were done as a functional anastomosis (side-to-side) extracorporeally by linear stapler 80 . The omental opening was not closed upon completion of the anastomoses. For left sided procedures the distal resection was done by Echelon Flex $60 \mathrm{~mm}$ Stapler, Green Cartridge (Ethicon Endo-Surgery, Inc., Blue Ash, Ohio, USA). The colon was then taken out of the port and the proximal resection completed extracorporeally. After introduction of the anvil of EEA stapler the colon was progressed within the abdomen, the port cap replaced and insufflated. The anastomoses were then completed intracorporeally by EEA ${ }^{\mathrm{TM}} 31 \mathrm{~mm}$ DST Series with $4,8 \mathrm{~mm}$ Staples (Covidien, Mansfield, USA). For subtotal colectomies the resection was begun from the right and then moved to the left colon. The colon was taken out of the port and the ileal resection performed extracorporeally. The anvil of the stapler was introduced to the side wall and the end of the ileal segment closed manually. After progression of the ileal segment within the abdomen the ileorectal anastomoses were completed in an end-to-side manner via circular stapler intracorporeally. A silicone drain was placed in the pelvis through the left lower quadrant, in patients who had a low anterior resection for rectal cancer. After completion of the operation the fascia was closed with long lasting absorbable suture materials, and the incision was closed with interrupted sutures (Figure 3).
Table 1. Demographic data

\begin{tabular}{|lccc|}
\hline & All cases & \multicolumn{3}{c}{ S-LCS cancer } & S-LCS benign \\
\hline Male/female & $13 / 11$ & $6 / 7$ & $7 / 4$ \\
\hline Age (interval) & $58(22-89)$ & $63(43-89)$ & $53(22-75)$ \\
\hline BMI (interval) & $26(23-39)$ & $26(23-37)$ & $27(24-39)$ \\
\hline ASA group & & & \\
\hline I & 14 & 6 & 8 \\
\hline II & 10 & 7 & 3 \\
\hline Previous abdominal surgery & 4 & 1 & 3 \\
\hline Emergency & 2 & 2 & 0 \\
\hline Radiologic tumor size & - & $4.4(2.4-6)$ & - \\
\hline
\end{tabular}

Table 2. Postoperative results

All cases S-LCS cancer S-LCS benign

Duration (minutes) $\quad 177(110-363) \quad 187(110-363) \quad 168(120-300)$

$\begin{array}{llll}\text { Drain } & 4 & 4 & 0\end{array}$

\begin{tabular}{lccc} 
Length of hospital stay (days) & $5.35(4-11)$ & $5.6(4-11)$ & $5.1(4-8)$ \\
Follow-up (months) & $10.7(2-26)$ & & \\
Flatus (days) & $2.7(2-5)$ & $3(2-5)$ & $2.5(2-4)$ \\
\hline Oral diet (days) & $2.9(2-6)$ & $3(2-6)$ & $2.8(2-4)$ \\
Tumor size (cm) & - & $4.3(2-5.6)$ & - \\
Tumor lymph node & - & $23(14-33)$ & -
\end{tabular}

$\begin{array}{llll}\text { Complications } & & & \\ \text { Wound infection } & 1 & 1 & 0 \\ \text { Ureter injury } & 1 & 0 & 1 \\ \text { Postop ileus } & 1 & 1 & 0\end{array}$

Concomitant surgical procedure

$\begin{array}{llll}\text { Port replacement } & 2 & 2 & 0 \\ \text { Hiatal hernia repair } & 1 & 1 & 0 \\ \text { Cholecystectomy } & 1 & 0 & 1\end{array}$

\section{RESULTS}

Eleven of the 24 patients had benign and 13 had malign diseases. The male to female ratio was $11 / 13$, and the mean age $58(22-89)$ years.

Eleven patients were operated for benign conditions. One patient underwent right hemicolectomy for Crohn's disease, 1 patient underwent anterior resection for rectal prolapse, 8 patients with diverticulitis and 1 patient with diverticular bleeding had sigmoid colectomy. Single incision colon resection was performed in 13 patients for malignancy. Two right hemicolectomy, 3 left hemicolectomy, 3 sigmoid colectomy, 3 low anterior resection and 2 subtotal colectomy were done. Two patients were operated emergently due to partial obstruction due to left sided colon tumor. A nasogastric tube and urinary catheter were preoperatively placed in all patients to be withdrawn at the $12^{\text {th }}$ postoperative hour. 


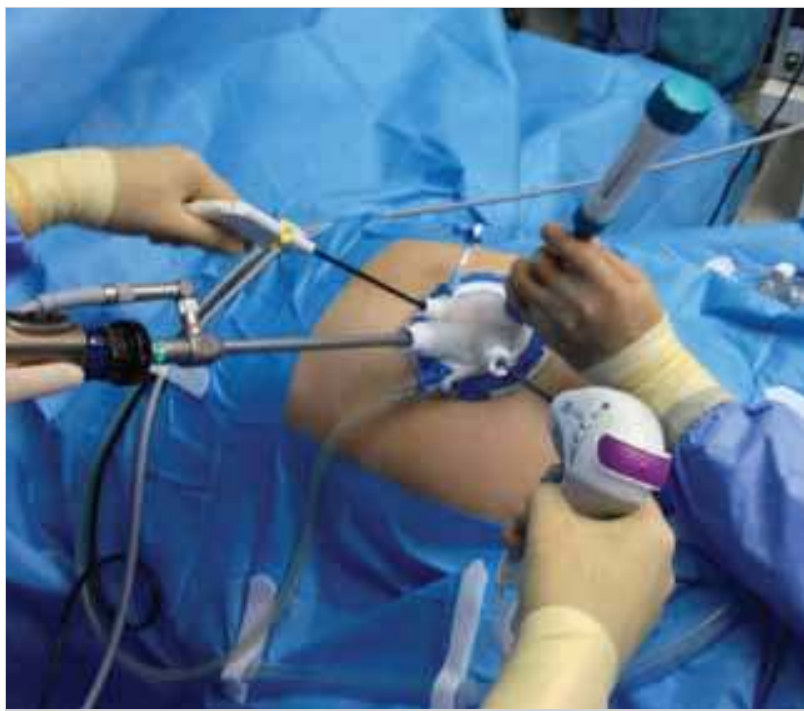

Figure 1. Use of the placed Octoport
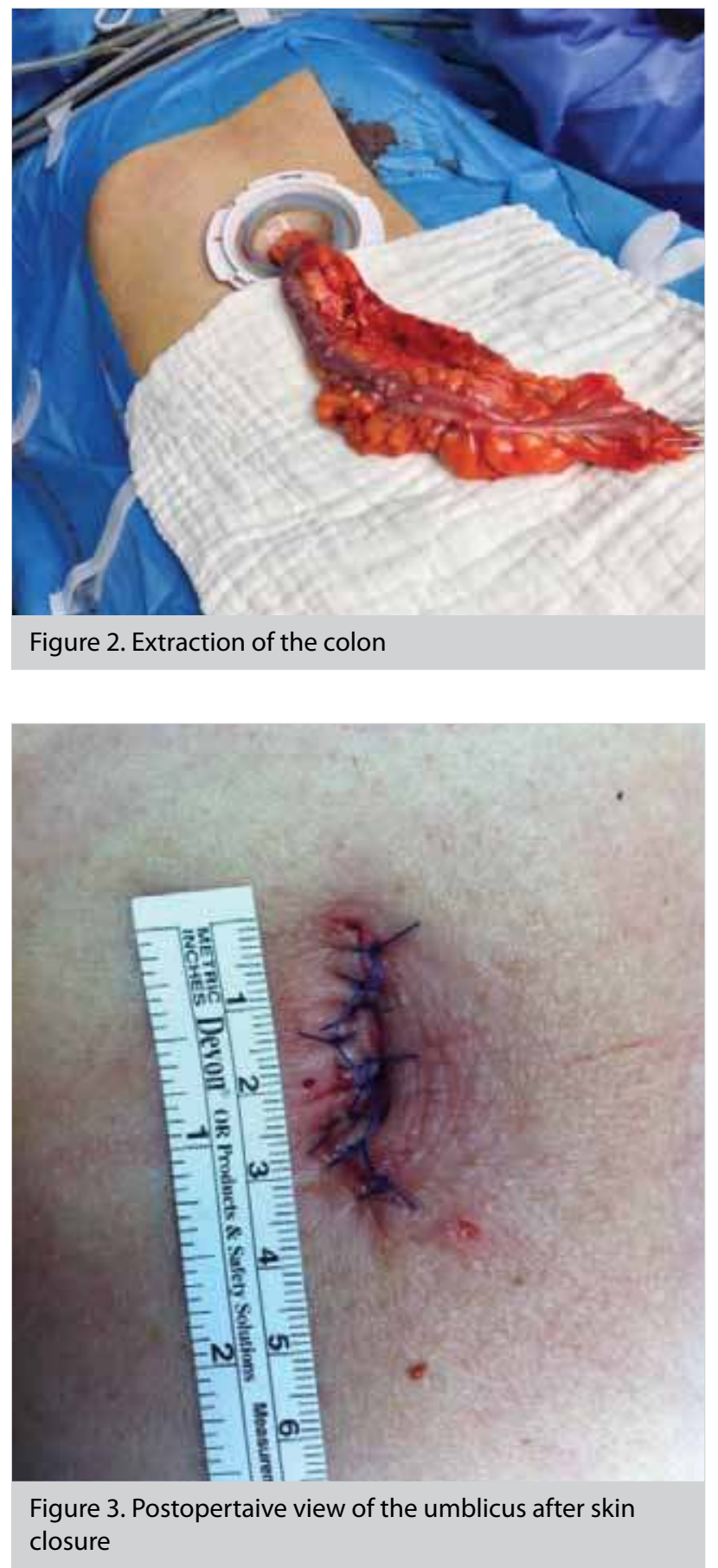

during the water test in the colorectal anastomosis line, and was secured with intracorporeal seromuscular sutures.

A surgical drain was used in 4 (16.6\%) patients. A pelvic drain was inserted through the left lateral quadrant, in patients who presented with obstruction and underwent low anterior resection. The mean operating time was 177 (110-363) minutes. The longest case was the patient who had a colon tumor and received concurrent hiatal cruroraphy.

Mean length of hospital stay was 5.35 (4-11) days. The nasogastric tube was withdrawn after 12 hours except the patient who developed ileus. Oral intake was begun at the second postoperative day. The mean time to first gas discharge was 2.25 (2-5) days. Mean follow-up was 10.7 (2-26) months. The 
sutures were removed at the $10^{\text {th }}$ postoperative day and patients were scheduled for a follow up on the $1^{\text {st }}$ month. Patients with tumors were referred to Oncology (Table 2).

\section{DISCUSSION}

Since single incision single port laparoscopic surgical procedures are performed by surgeons alone it brings up issues regarding the learning curve. In the USA conventional laparoscopic colorectal surgery is performed by $25 \%$ of surgeons (5, 6). Since experienced surgeons are currently in the process of learning conventional laparoscopic procedures, it remains to be seen how popular S-LCS will get.

Single incision laparoscopic surgery is being evaluated for its superiority on conventional laparoscopic surgery regarding minimally invasive properties, but for the time being the main benefit seems to be its scarless feature. The remaining issues are being assessed by comparative studies. Length of hospital stay is a significant minimal invasive criteria but Japanese patients asking to stay longer in the hospital have an effect on this parameter (3). There is a similar expectation in our country as well. We believe the contributing factors for this request are that patients feel safer in the hospital and daily bed costs are low. Mean length of hospital stay varies between 4 to 10 days in some studies $(1,3,7,8)$. Park et al. (4) compared this technique with conventional laparoscopic colorectal surgery (C-LCS) and found that blood loss, resection margin length, and morbidity were similar but the operation time in single port surgeries were shorter. Mean length of hospital stay was 5,35 days in our series. The patient who was hospitalized for 11 days due to paralytic ileus has raised the mean.

Besides studies reporting shorter length of hospital stay as compared to C-LCS (3), Fung et al. (9) published an analytical review stating that the subject of shorter length of stay in SLCS was debatable.

Another important subject is the variety in technique. Technology is currently in the process of evolving. Devices are being developed upon surgeon's request. Especially in Far Eastern studies, homemade ports where fingers of a glove are used as multi-entrance ports are preferred (10). Another method is to insert three different ports from a single incision (11).

Disadvantages of this technique are; requirement for angulated instruments which can be difficult to manipulate, clashing of instruments during the procedure and loss of pneumoperitoneum due to gas leakage (3). We preferred to use OctoPort $\left(\right.$ OCTO $^{\text {TM }}$ Port, Dalim Surgnet, Seoul, South Korea) which is a single port with multi port entrance properties in our cases. The previously mentioned disadvantages are not encountered in the port we selected. The operation could be carried out with standard conventional instruments. Similar port set-ups (Gelport, Covidien SILS port etc.) have been used in various studies $(1,12,13)$. Another property of the port we used is that it does not require additional Alexis device to protect the incision site especially in cancer patients.
The number of lymph nodes harvested and safety margin of the specimen are factors that control the oncologic appropriateness of the applied technique. The number of lymph nodes resected varies between 12 to $38(3,7,9,13-16)$. In our series a mean of 23 (14-33) lymph nodes were excised in the 13 patients with malignancy. In all cases the margins were safe enough after pathologic evaluation.

The operation duration is reported to be between 75-229 minutes $(1,7,11,13-15,17)$. Although S-LCS is a more challenging technique and lasts longer than C-LCS, in our series the mean operation time was 177 minutes $(3,6)$. The factors that lengthened our operation times are; 2 patients requiring subtotal colectomy, dissection of the shortened mesentery in patients with diverticular disease, and additional surgery requirements in 4 patients.

Mortality is reported to be $0-0.4 \%$ and morbidity $7.5-13 \%$ (2, $11,15)$. There is no mortality in our series, and the morbidity rate is $12.5 \%$. The late left ureteral thermal injury was accepted as a major morbidity.

Van den Boezem et al. (18) reported on two incisional hernias. We believe such incisional hernias might cause problems in the long-term results of single incision laparoscopic surgery. Mynster et al. (16) reported a small bowel injury.

None of our patients required conversion to open surgery. Requirement for an additional port for S-LCS is reported as $5-10 \%$, with conversion to open surgery rates of $4-6 \%(8,11$, $14,15,17,18)$. We preferred to use a pelvic drain placed from the left lower quadrant in 4 of our patients after single incision surgery. Although in some studies the single incision site (umbilicus) is used as the drain site, we believe this might result in wound infection and create basis for incisional hernia formation.

None of our patients required stoma formation. In patients with a prior plan to place a stoma the single port site can be decided according to the stoma site therefore still being able to apply minimal scarless surgery (13).

The failure of this approach is generally thought to result from adhesions and localization of the tumor (4). It is emphasized that standardization of the technique is essential (13). Kanakala et al. (2) compared S-LCS with C-LCS and found that most of the parameters are similar between the two groups. However, they stated that the two groups were not identical, with patients in the single incision group being younger with a lower rate of malignancy. The fact that this procedure is currently being used with caution for carefully selected patients shows that further comparative studies are required.

\section{CONCLUSION}

S-LCS offers scar-less surgery without compromise from oncological principles, however it has no proven superiority over CLCS. These factors will determine the future of this surgery together with technological developments. The feasibility of the technique described in this report and our short-term results 
are parallel with the literature. We believe for the time being SLCS can be used in selected cases by experienced laparoscopic surgeons.

\section{Conflict of Interest}

No conflict of interest was declared by the authors.

Peer-review: Externally peer-reviewed.

Informed Consent: Written informed consent was obtained from patients who participated in this study.

\section{Author Contributions}

Concept - M.E.; Design - M.E., H.G.; Supervision - M.E.; References - M.E., H.G, E.Ö.; Materials - M.E., H.G, E.Ö.; Data Collection and/or Processing - H.G.; Analysis and/or Interpretation - M.E., H.G.; Literature Review - M.E., H.G.; Writer - H.G.; Critical Review - M.E.; Other - H.G, E.Ö.

\section{REFERENCES}

1. Remzi FH, Kirat HT, Kaouk JH, Geisler DP. Single-port laparoscopy in colorectal surgery. Colorectal Dis 2008; 10: 823-826. [CrossRef]

2. Kanakala V, Borowski DW, Agarwal AK, Tabaqchali MA, Garg DK, Gill TS. Comparative study of safety and outcomes of single-port access versus conventional laparoscopic colorectal surgery. Tech Coloproctol 2012; 16: 423-428. [CrossRef]

3. Egi $\mathrm{H}$, Hattori $M$, Hinoi T, Takakura $Y$, Kawaguchi $Y$, Shimomura $M$, et al. Single-port laparoscopic colectomy versus conventional laparoscopic colectomy for colon cancer: a comparison of surgical results. World J Surg Oncol 2012; 10: 61. [CrossRef]

4. Park SJ, Lee KY, Kang BM, Choi Sl, Lee SH. Initial experience of single-port laparoscopic surgery for sigmoid colon cancer. World J Surg 2013; 37: 652-656. [CrossRef]

5. Guller U, Jain N, Hervey S, Purves H, Pietrobon R. Laparoscopic vs open colectomy: outcomes comparison based on large nationwide databases. Arch Surg 2003; 138: 1179-1186. [CrossRef]

6. Steele SR, Brown TA, Rush RM, Martin MJ. Laparoscopic vs open colectomy for colon cancer: results from a large nationwide populationbased analysis. J Gastrointest Surg 2008; 12: 583-591. [CrossRef]
7. Chew MH, Wong MT, Lim BY, Ng KH, Eu KW. Evaluation of current devices in single-incision laparoscopic colorectal surgery: a preliminary experience in 32 consecutive cases. World J Surg 2011; 35 : 873-880. [CrossRef]

8. Vestweber B, Galetin T, Lammerting K, Paul C, Giehl J, Straub E, et al. Single-incision laparoscopic surgery: outcomes from 224 colonic resections performed at a singlecenter using SILS. Surg Endosc 2013; 27: 434-442. [CrossRef]

9. Fung AK, Aly EH. Systematic review of single-incision laparoscopic colonic surgery. Br J Surg 2012; 99: 1353-1364. [CrossRef]

10. Choi SI, Lee KY, Park SJ, Lee SH. Single port laparoscopic right hemicolectomy with D3 dissection for advanced colon cancer. World J Gastroenterol 2010; 16: 275-278. [CrossRef]

11. Brunner W, Schirnhofer J, Waldstein-Wartenberg N, Frass R, Weiss H. Single incision laparoscopic sigmoid colon resections without visible scar: a novel technique. Colorectal Dis 2010; 12: 66-70. [CrossRef]

12. Waters JA, Rapp BM, Guzman MJ, Jester AL, Selzer DJ, Robb BW, et al. Single-port laparoscopic right hemicolectomy: the first 100 resections. Dis Colon Rectum 2012; 55: 134-139. [CrossRef]

13. Diana M, Dhumane P, Cahill RA, Mortensen N, Leroy J, Marescaux J. Minimal invasive single-site surgery in colorectal procedures: Current state of the art. J Minim Access Surg 2011; 7: 52-60.

14. Katsuno G, Fukunaga M, Nagakari K, Yoshikawa S, Ouchi M, Hirasaki Y. Single-incision laparoscopic colectomy for colon cancer: early experience with 31 cases. Dis Colon Rectum 2011; 54: 705-710. [CrossRef]

15. Makino T, Milsom JW, Lee SW. Single-incision laparoscopic surgeries for colorectal diseases: early experiences of a novel surgical method. Minim Invasive Surg 2012; 2012: 783074.

16. Mynster T, Hammer J, Wille-Jørgensen P. Preliminary results after single-port laparoscopic colonic surgery. Dan Med J 2012; 59: 4551.

17. Gaujoux S, Maggiori L, Bretagnol F, Ferron M, Panis Y. Safety, feasibility, and short-term outcomes of single port access colorectal surgery: a single institutional case-matched study. J Gastrointest Surg 2012; 16: 629-634. [CrossRef]

18. Van den Boezem PB, Sietses C. Single-incision laparoscopic colorectal surgery, experience with 50 consecutive cases. J Gastrointest Surg 2011; 15: 1989-1994. [CrossRef] 